\title{
AN EPIDEMIOLOGICAL STUDY TO FIND OUT RISK FACTORS OF MULTI DRUGS RESISTANCE TUBERCULOSIS IN NEPAL
}

Bichha R.P, Jha K.K, Salhotra V.S, Weerakoon A.P, Karki K.B., Bichha Navneet

\begin{abstract}
Introduction:

Drug resistant tuberculosis is a threat to tuberculosis control worldwide. Previous anti- tuberculosis treatment is a widely reported risk factor for multi drug resistant tuberculosis (MDR-TB), whereas other risk factors are less well described. In Nepal National Tuberculosis Control Programme initiated DOTSPLUS Pilot project from September 2005 using standardized treatment regimen.
\end{abstract}

\section{Objective:}

To explore the risk factors for MDR-TB in Nepal.

\section{Methodology:}

Institution based matched case control study with a case: control ratio of 1:2 was carried out in three regions of Nepal. Fifty five cases and 110 controls were selected. Current MDR- TB patients on treatment from DOTS -Plus clinic were enrolled as cases. Controls were age, sex matched cured TB patients and who had completed treatment either from the same centre or any DOTS Centre adjacent to that DOTS Plus Centre. Data was collected by a trained research assistant using interviewer administered structured questionnaire. Matched analysis was done using SPSS 16 version. Confounding effects were controlled by using matching, matched analysis and regression analysis.

\section{Results:}

In matched analysis following were the significant risk factors for MDR-TB in Nepal.(1) HIV Sero positivity (OR 15.9, Cl 1.9- 133.0) (2) Travel cost more than 50 NRs per day (OR 6.5, Cl 2.4- 9.8) (3) Contact history of TB (OR 3.8, Cl 2.2- 6.6) (4)Living in a nuclear family ( OR 6.0, Cl 2.6- 13.9)(5) Non adherence to DOTS ( OR 18.6, $\mathrm{Cl} 2.27$ - 151.0) (6) Distance to treatment centre more than $5 \mathrm{Km}$ ( OR 3.9, Cl 1.5- 10.) (7)Previous history of TB ( OR 12.0, $\mathrm{Cl} 5.4$-26.5)(8) Living in a rural area (OR 4, $\mathrm{Cl}$ 2.1- 8.5) (9) Unmarried (Crude OR 3.3,Cl 1.6- 6.8) (10) Un employment ( OR 3.4,Cl 1.6-7.6)(11) Living in a rented house ( OR 3.5, $\mathrm{Cl}$ 1.77- 3.67) (12) Single bed room (OR 2.8, Cl 1.13-6.9).Using muti-variate analysis except living in a rented house and single bed room other variables were positive significant predictors for MDR -TB in Nepal.

\section{Conclusions:}

Many risk factors were related to the DOTS. Strengthening of DOTS programme to tackle the identified risk factors can reduce the MDR -TB burden in Nepal.

Key Words: MDR TB, Case Control Study, Risk Factor.

\section{Correspondence:}

Dr. Ajith Weerakoon,

Epidemiologist,

SAARC TB and HIVIAIDS Centre, Kathmandu, Nepal.

Email: saarctb@mos.com.np 


\section{INTRODUCTION}

Multidrug- resistant TB (MDR-TB) caused by Mycobacterium tuberculosis resistant to both isoniazid and rifampicin with or without resistance to other drugs is among the most worrisome elements of the pandemic of antibiotic resistance because TB patients that fail treatment have a high risk of death ${ }^{(1)}$. Globally, about three percent of all newly diagnosed patients have MDR-TB.MDR-TB has a lower cure rate and treatment cost being almost 100 times more than treating a drug -susceptible TB patient, it is imperative that this problem be addressed on a priority .

World Health Organization estimated TB prevalence and incidence rate of all forms of TB respectively 215 and 158 per 100000 populations in 2014. With the introduction of Directly Observed Treatment Short course (DOTS) number of deaths has dramatically reduced from $9,712(51 / 100000)$ in 1990 to $(17 / 100$ 000 ) in 2014. Total 35277 notified new and relapse cases were detected, among the notified new and relapse cases $345(<1 \%)$ cases aged under 15 years. However male female ratio is 1.8 in 2014. Treatment success rate among new smear-positive cases was $91 \%$ for the cohort of patients registered in 2013 , and has been consistently above the target of $85 \%$ since 2001 . The success rate among new smear-negative/extra pulmonary and retreatment cases is high. ${ }^{(2)}$.

Tuberculosis is one of the major public health problems in Nepal. About $45 \%$ of the total population is infected with TB, out of which $60 \%$ are in the productive age group. Every year about 44,000 people develop active TB, of whom 20,000 have infectious pulmonary disease. These 20,000 are able to spread the disease to others.

In 1994 the National Tuberculosis Program (NTP) piloted Directly Observed Short Course (DOTS) in four districts with total population coverage of $1.7 \%$. The Tuberculosis program is delivered in the 75 districts of Nepal through the Hospitals, Health Centers and Sub -Health Posts by staff for whom TB treatment is part of their integrated health care activities. In Nepal clinic based ambulatory treatment for Tuberculosis is the norm.

Tuberculosis control is identified as a top priority programme within the Ministry of Health and Population. Full DOTS institutional coverage was reached in the primary health system, including $100 \%$ coverage in PHC centers, health posts, and sub-health posts in the country. Decentralization of services, outreach projects and strong community involvement are contributing significantly to increase case-detection and access to TB diagnosis and treatment.

\section{SIZE OF THE MDR- TB PROBLEM IN NEPAL:}

Anti tuberculosis drug resistance is a great public health problem, which may become a great challenge for the National TB control program. Of all patterns of drug resistance MDR -TB which is resistant to at least Rifampicin and Isoniazid is the one that focused international attention because of the reduced response to standard Short -Course Chemotherapy (SCC) with first line drugs, leading to higher mortality and treatment failure rates and increased period of transmissibility.

The percentage of TB cases with MDR-TB 2.2\% and retreatment cases was $15 \%$ in 2014. However, total MDR-TB burden in the country was 1160 . National TB Programme has undertaken four national surveys in Nepal as part of the WHO/ IUATLD Global Project on Anti -Tuberculosis Drug Resistance Surveillance. The first survey, in 1996, showed a prevalence of multi drug-resistance (resistance to at least Rifampicin and Isoniazid) around 1.2\% among patients never previously treated for tuberculosis. Similarly Drug Resistance prevalence was 3.8\% in 1998, 1.3\% in 2001 and $2.9 \%$ in 2006 and 2.2 in 2010. Nepal was one of the first countries globally to introduce ambulatory MDR-TB case management in 2005 diagnosing and treating Category II failures and other laboratory-confirmed MDR-TB cases under a GLC approved project. According to WHO Anti Tuberculosis Drug Resistance in the World Report No 4 published in 2008 "the Nepal has proven to be the leader in MDR-TB control in the region by establishing the first MDR-TB control programme in the public sector and expanding it's coverage to $100 \%$ of the country by the end of 2006 ". (2)

Although its causes are microbial, clinical and programmatic, drug -resistant TB is eventually a man made phenomenon. An inadequate or poorly administered treatment regimen allows a drug resistant strain to become the dominant strain in a patient infected with TB. There are many studies conducted in the developed world to find out causes of MDR -TB but in the developing world specially in the SAARC region such studies are scarce. Hence this study was conducted in Nepal to achieve the following objectives.

To determine risk factors for multi-drug resistance in patients with pulmonary tuberculosis in Nepal.

\section{METHODOLOGY:}

\section{Study Design}

Institution based matched case - control study with a Case: Control ratio of 1:2 was carried out in order to identify the predisposing risk factors of MDR-TB in Nepal.

J ournal of Tuberculosis, Lung Diseases and HIV/AIDS 


\section{Study Setting}

Selected institutions in Central Western and Eastern region in Nepal where the DOTS PLUS PILOT Project were carried out were the focal point for the study. (Kathmandu valley, Biratnagar and Pokhara) . These areas were selected considering feasibility and case load of MDR -TB patients in each region .

\section{Definition of cases and controls}

\section{Definition of cases}

A sample of patients who were diagnosed as having MDR TB (sputum culture and sensitivity confirmed) and who is permanent resident of Nepal were recruited for the study as a case.

\section{Exclusion criteria:}

MDR-TB patients less than 15 years of age.

\section{Definition of controls}

Controls were age -sex matched cured TB patients (who are not diagnosed as having MDR-TB) and who have completed TB treatment either from the same centre or any DOTS centre adjacent to that DOTS Plus centre.

\section{Case: Control Ratio}

To enhance the power of the study one case to two controls (1:2) were taken after consideration of the cost and precision of the study.

\section{Matching}

Two controls were matched with each case by

$$
\begin{aligned}
& \text { a. Age ( } \pm 2 \text { year) } \\
& \text { b. Sex (same) }
\end{aligned}
$$

Sample size estimation and Sampling method Parameters used in the calculation of sample size: The proportion of the general population exposed to risk factors $\left(P_{0}\right)$ and Odds Ratio worth detecting $(R)$ are the parameters needed in calculation of the sample size of a case -control study according to the following equation ${ }^{(3)}$

$$
\frac{N=(1+1 / C) p^{-1} q^{-1}(Z \alpha+Z \beta)^{2}}{\left(P_{1}-P_{0}\right)}
$$

Where

$\mathrm{N}=$ Sample size

$Z \alpha=$ Level of significance $=0.05$

$Z \beta=$ Power of the study $=85 \%=0.15$

$\mathrm{P}_{0}=$ Proportion exposed among general population

$=$ Prevalence of default from TB treatment $=26.8 \%$ $=25 \%{ }^{(4)}(5)$

$\mathrm{C}=$ Number of controls $=2$

OR worth detecting $=2$

Accordingly

No of cases $=55$

No of Controls $=110$

In a situation where multiple risk factors are considered, the ideal would be to calculate the sample size using lowest proportion exposed among general population $\left(\mathrm{P}_{0}\right)$ and Odds Ratio associated with risk factor since it gives the largest sample size.

After conducting thorough literature review prevalence of default from TB treatment will be taken as $25 \%$ for following reason. ${ }^{(4)}$

It is (defaulter from TB treatment) considered as the one of the most important variable influencing the MDR -TB and this figure is considered relatively small figure compared to the proportion of the exposure due to other risk factors of MDR-TB. (E.g. substance abuse) Also this study is from developing country which is similar to Nepal context.

Therefore the required sample size of 55 subjects was collected as a consecutive sample diagnosed as having MDR-TB in Nepal.

Number of cases $=55$

Number of controls $=110$

Total number of subjects $=165$

\section{Sampling method for cases:}

For this study following DOTS Plus centers and DOTS Centers were selected from Central, Western and Eastern region. (Table 1) 
Table 1:DOTS Plus Centres and DOTS Centres selected for the study

\begin{tabular}{|l|l|l|l|l|}
\hline Region & \multicolumn{1}{|c|}{$\begin{array}{c}\text { DOTS PLUS } \\
\text { Centre }\end{array}$} & \multicolumn{1}{|c|}{ DOTS Centre } & \multicolumn{1}{|c|}{$\begin{array}{c}\text { No of } \\
\text { Cases }\end{array}$} & \multicolumn{1}{c|}{$\begin{array}{c}\text { No of } \\
\text { Controls }\end{array}$} \\
\hline Central & National TB Centre & Thimi Health Post & 15 & 30 \\
\hline Central & GENETUP - Kalimati & $\begin{array}{l}\text { GENETUP - Kali- } \\
\text { mati }\end{array}$ & 10 & 20 \\
\hline Western & $\begin{array}{l}\text { Regional TB Centre - } \\
\text { Pokhara }\end{array}$ & $\begin{array}{l}\text { Regional TB Centre } \\
\text { - Pokhara }\end{array}$ & 15 & 30 \\
\hline Eastern & NATA, Morang & NATA, Morang & 15 & 30 \\
\hline Total & & & 55 & 110 \\
\hline
\end{tabular}

Fifty five MDR-TB cases were randomly selected from above centres using lottery method. Since proportionately higher number of cases are getting treatment from Central region more cases were recruited from Central region.

Sampling method for controls:

Age, sex matched controls were selected randomly from the cured TB patients which registered in the DOTS registry which is kept in the above centers. If the DOTS Plus centre has no DOTS Centre, adjacent DOTS Centre was selected for the controls selection (Ex: NTC- Nepal is only a DOTS Plus centre, hence adjacent DOTS centers (Thimi Health Post ) was selected for this study. ) Controls were interviewed in their residence with prior appointment. Every effort was taken to preserve confidentiality during interview.

\section{Data Collection Technique}

Data was collected by a team of researchers from National TB Programme, Nepal and SAARC TB and HIVIAIDS Centre using an interviewer administered, pre coded structured questionnaire for both cases and controls. Informed consent was obtained from all the cases and controls before interviewing them. The consent of the cases and controls was obtained in the same manner.

\section{Ethical Consideration:}

The following ethical issues were considered in the design of the study.

- The cases and controls were briefed regarding the nature, objectives, and method of the study and their voluntary participation acquired.

- Cases and controls were given the option to withdraw from the study at any point of time.

- Total confidentiality with regard to the identification of the cases and controls was assured at all times during and after the study.

- Permission and Consent were obtained from relevant authorities (National TB Control Programme) before commencement of the study.

\section{Data collection instrument}

An interviewer administered, pre coded, structured questionnaire was used to collect data. This questionnaire consisted of the following components.

- Socio -Demographic data

- Details of previous and current Tuberculosis status

- Details of previous treatment history and contact history

- Details of previous/present medical and surgical history

- Knowledge and barriers to adhere DOTS

- Quality of professional -patient interaction

- Details of social history

\section{Statistical Analysis:}

Statistical analysis was done using SPSS Version 16 soft ware package.

The following steps were followed to analyze the data

1. Basic assessment of the crude risk of MDR-TB by calculating the crude Odds Ratio through univariate analysis.

2. Controlling of confounding effects done by using Matched analysis and Multivariate analysis. 
RESULTS:

Table 2 shows the Socio Demographic variables of cases and controls

\begin{tabular}{|c|c|c|c|c|}
\hline Variables & Cases & Controls & Odd Ratio $(95 \% \mathrm{Cl})$ & Significant \\
\hline Other Religion & $8(34.8)$ & $16(65.2)$ & & \\
\hline Hindu & 47 (33.3) & $94(66.6)$ & $1(0.4-2.5)$ & Not significant \\
\hline Illiterate & $13(26.6)$ & $33(73.4)$ & & \\
\hline Literate & $\begin{array}{c}42 \\
(35.8)\end{array}$ & $\begin{array}{c}77 \\
(64.1)\end{array}$ & $\begin{array}{c}0.65 \\
(0.31-1.38)\end{array}$ & Not significant \\
\hline Unmarried & $33(41.8)$ & $46(58.2)$ & & \\
\hline Married & $22(35.6)$ & $64(74.4)$ & $2.1(1.07-4.01)$ & Significant \\
\hline Unemployed & $26(57.7)$ & $19(42.2)$ & & \\
\hline Employed & $29(24.2)$ & $91(75.8)$ & $4.395(2.1-8.7)$ & Significant \\
\hline $\begin{array}{l}\text { Monthly family income } \\
\text { Less than NRs } 5000\end{array}$ & $\begin{array}{c}37 \\
(30.7)\end{array}$ & $\begin{array}{c}63 \\
(63.0)\end{array}$ & & \\
\hline $\begin{array}{l}\text { Monthly family } \\
\text { income } 5000 \text { or } \\
\text { more NRs }\end{array}$ & $\begin{array}{c}18 \\
(27.7)\end{array}$ & $\begin{array}{c}47 \\
(72.3)\end{array}$ & $1.53(0.78-3.03)$ & Not significant \\
\hline Nuclear & $48(40.3)$ & $71(59.7)$ & & \\
\hline Extended & $07(15.2)$ & $39(84.8)$ & $3.8(1.58-9.050$ & Significant \\
\hline $\begin{array}{l}\text { Place of living } \\
\text { (Other's home) }\end{array}$ & $30(51.7)$ & $28(48.3)$ & & \\
\hline $\begin{array}{l}\text { Place of living(Own } \\
\text { home) }\end{array}$ & $25(23.4)$ & $82(76.6)$ & $3.5(1.77-3.67)$ & Significant \\
\hline $\begin{array}{l}\text { Number of bed } \\
\text { rooms-one }\end{array}$ & $12(54.5)$ & $10(45.5)$ & & \\
\hline $\begin{array}{l}\text { Number of bed rooms } \\
\text { more than one }\end{array}$ & $43(30.0)$ & $100(70.0)$ & $2.8(1.13-6.90)$ & Significant \\
\hline $\begin{array}{l}\text { Plaace of } \\
\text { living -Rural }\end{array}$ & $29(55.8)$ & $23(44.2)$ & & \\
\hline Urban & $26(23.0)$ & $87(77.0)$ & $4.2,(2.1-8.5)$ & Significant \\
\hline Current smoker & $14(35.0)$ & $26(65.0)$ & & \\
\hline Not a current smoker & $41(32.8)$ & $84(67.2)$ & $1.10(=0.5-2.4)$ & Not significant \\
\hline $\begin{array}{l}\text { Regular } \\
\text { Alcoholics }\end{array}$ & $43(37.4)$ & $72(62.6)$ & & \\
\hline $\begin{array}{l}\text { No taking alcohol for } \\
\text { past } 5 \text { years }\end{array}$ & $12(24.0)$ & $38(76.0)$ & $1.89(0.86-3.85)$ & Not significant \\
\hline
\end{tabular}

Religion other than Hindu, literate persons current smoking, alcoholics and, monthly family income less than 5000 NRs have higher risk of getting MDR-TB. But these associations were statistically not significant. There was a significant association of getting MDR-TB and unmarried civil status, unemployment living in nuclear family, not living in their own home, living in rural area and only one bed room in the house. 
Table 3: shows the comparison of disease related variables among cases and controls

\begin{tabular}{|l|l|l|l|l|}
\hline \multicolumn{5}{|c|}{ Table 3: Disease related comparison of cases and controls } \\
\hline Variables & Cases & Controls & $\begin{array}{l}\text { Crude } \\
\text { Ratio(95\%Cl) }\end{array}$ & Significant/not \\
\hline Previous history of TB-Present & $53(46.0)$ & $62(54.0)$ & & \\
\hline No previous history of TB & $02(4.0)$ & $48(96.0)$ & $20.5(4.76-88.2)$ & Significant \\
\hline & & & & \\
\hline Contact history of TB & $33(52.4)$ & $30(47.6)$ & & \\
\hline No contact history of TB & $22(21.6)$ & $80(78.4)$ & $4.95(2.0-7.9)$ & Significant \\
\hline & & & & \\
\hline HIV Positive & $07(87.5)$ & $01(47.6)$ & & Significant \\
\hline HIV Negative/Unknown & $48(30.6)$ & $109(78.4)$ & $15.9(1.92-133)$ & \\
\hline & & & & Significant \\
\hline Non regularity of TB treatment & $08(88.9)$ & $01(11.1)$ & & \\
\hline TB treatment taken regularly & $45(28.8)$ & $109(71.2)$ & $19.4(2.27-151)$ & \\
\hline & & & & Significant \\
\hline $\begin{array}{l}\text { Distance to DOTS clinic more } \\
\text { than 5Km }\end{array}$ & $13(61.9)$ & $08(38.1)$ & & \\
\hline $\begin{array}{l}\text { Distance to DOTS clinic less } \\
\text { than 5 Km }\end{array}$ & $42(29.2)$ & $102(70.8)$ & $3.95,(1.52-10.2)$ & Significant \\
\hline $\begin{array}{l}\text { Travel cost to treatment centre } \\
\text { more than 50Nrs per day }\end{array}$ & $15(71.4)$ & $06(78.6)$ & & $6.5,(2.36-9.78)$ \\
\hline $\begin{array}{l}\text { Travel cost to treatment centre } \\
\text { less than 50Nrs per day }\end{array}$ & $40(27.8)$ & $104(72.2)$ & \\
\hline
\end{tabular}

There was a significant association of getting MDR-TB and previous history of TB, contact history of TB, HIV positive patients, non regularity of TB treatment, distance to DOTS clinic more than $5 \mathrm{Km}$, and travel cost to treatment centre more than $50 \mathrm{Nrs}$ per day

Final fitted model for multi variety analysis for the selected risk factors were done. Results are shown in Table 4.

Table 4: Final fitted model for multi variate analysis for the selected risk factors

\begin{tabular}{|l|l|l|l|l|}
\hline Variable & $\mathrm{aOR}$ & $\mathrm{df}$ & $\mathrm{p}$ & Significant/not \\
\hline Past Un-employment & 4.87 & 1 & 0.000 & Significant \\
\hline Un-married & 2.24 & 1 & 0.016 & Significant \\
\hline Nuclear family & 4.5 & 1 & 0.002 & Significant \\
\hline Not living in own house & 2.1 & 1 & 0.608 & Not significant \\
\hline Having only one bed room & 1.34 & 1 & 0.956 & Not significant \\
\hline Previous history of TB & 14.54 & 1 & 0.000 & Significant \\
\hline Contact history of TB & 3.45 & 1 & 0.021 & Significant \\
\hline HIV positive & 13.2 & 1 & 0.000 & Significant \\
\hline Not adherence to DOTS & 16.8 & 1 & 0.000 & Significant \\
\hline Distance more than 5Km & 3.6 & 1 & 0.03 & Significant \\
\hline Travel cost > than 50 NRs & 5.8 & 1 & 0.002 & Significant \\
\hline Living in rural area & 4.1 & 1 & 0.04 & Significant \\
\hline
\end{tabular}

oar- Adjusted Odds Ratio,df-Degree of freedom,

Except not living in own house and having only one bed room all other variables which were significant in the univariate analysis were significant in the multy variety analysis. 


\section{DISCUSSION:}

In the present study, the following factors were found as risk factors for MDR-TB: unemployment, unmarried civil status, those living in nuclear family, previous history of $T B$, contact history of TB, HIV positive status, non adherence to DOTS during previous treatment, travel cost to DOTS centre (more than 50 Nepali Rs), distance to DOTS centre (more than $5 \mathrm{Km}$ ), and living in a rural area. A study done by Ahmed et al (2003) in Pakistan identified history of TB treatment, being a male, belonging to $15-25$ years age group, having 1-5 years of schooling or having TB patient in the household as a risk factors for MDR-TB ${ }^{(5)}$. According to the study conducted in Peru by Pablo et al (2003), inadequate treatment regimen, poor adherence to treatment, and HIV infection were the risk factors for MDR-TB ${ }^{(6)}$.

In a case control study conducted in four European countries it was found that IV drug usage, asylum -seeker support as income factor, living in a nursing home, previous TB with pulmonary location, living in a prison, known TB contacts, and Immune suppression other than HIVI AIDS were the risk factors for MDR-TB ${ }^{(7)}$.

In the present study HIV infection was found to be as a risk factor for MDR-TB in Nepal. As reported in other studies from Sub Saharan Africa, and the recent Global project on drug resistance, no significant association was observed between the MDR-TB and HIV infection status in the new cases of MDR-TB ${ }^{(8)(9)(10)(11)}$. Numerous MDR-TB outbreaks have been documented in HIV patients, and in some areas of the world HIV is a risk factor for MDR-TB .(12)

One notable finding in the present study was that difficult and accessibility to health services due to the distance from the health centre being more than $5 \mathrm{Kms}$. was associated with one getting MDR-TB. The results suggests that patients with MDR-TB coming to the DOTS centre from more than $5 \mathrm{Km}$ away are at a great risk of developing MDR TB than patients living nearby to the health services facilities.

High travel cost (more than 50 NRs) may lead to poor patient compliance and be considered as a risk factor for MDR-TB. Previous studies have revealed that the non complaint patients spent more time and cost for traveling to the treatment centre than the compliant patients. The time spent traveling to the centre could be used for other purposes. For those in employment, travel time represents time absent from work.

Hence, non compliance with TB treatment was one of the strongest predictors of MDR-TB. Non compliance with treatment is not only harmful for the patients, but its consequence may be much more severe for the general population.

The substantially higher risk of MDR-TB among unemployed patients is possibly a function of socio economic status. Unemployment may have served as an indirect measure of the patient's functional and socio-economic status. Impoverished populations are well documented in many setting to have higher rates of TB than the general population. The cycle between poverty and TB is broadly recognized ${ }^{(13)}$.

Unmarried civil status was a risk factor for MDR-TB. On the premise that patients are less likely to default if they live with many family members mainly with wife and children who provide encouragement and remind to keep medical appointments than living alone or living with friends,

In the present study those individuals present in rural areas were at high risk for MDR-TB compared to urban areas as the rural inhabitants do not have the same level of access to health and social services as their urban counterpart. Similar findings were reported in study done by Boyte et al $2001^{(14)}$.

Patients in the present study who smoked tobacco were considered as at risk for MDR-TB. However it was statistically not found to be risk factor.

Though previous studies have reported that alcoholism is an important risk factor for MDR-TB, our study did not reveal that alcoholism contributed to MDR-TB. ${ }^{(15)}$.

Previous studies reported previous history of tuberculosis treatment is a significant risk factor for developing MDR-TB as in the present study (14).

The present study revealed that previous TB treatment is a risk factor for MDR-TB. In a study of 876 patients in a 6 countries, the re-treatment success rate was $57 \%$ and $29 \%$ with MDR-TB (16). Previous resistance surveillance conducted in Nepal also revealed higher rates of MDR-TB among re-treatment group ${ }^{(17)}$. These results suggest that the higher incidence of MDR-TB were inevitably associated with lower success rate in re treatment group.

Contact with a TB patient at home, in the work place, or elsewhere was a risk factor. These findings might be affected by recall bias because cases were perhaps more likely to remember a history of exposure than controls.

\section{CONCLUSION:}

1. Despite a successful implementation of a TB control programme in Nepal, drug resistant TB remains an important issue.

2. HIV sero-positivity $(\mathrm{OR}=15.9)$ was significantly associated with MDR-TB in Nepal

3. Travel cost of more than 50 NPR per day $(\mathrm{OR}=6.5)$ and distance of more than $5 \mathrm{KM}$ to DOTS centers were significant risk factors for MDR-TB.

4. Previous history of $T B$, contact history of $T B$ $(\mathrm{OR}=3.8)$ and previous non adherence to 
DOTS (OR=18.6) were significant risk factor for MDR-TB in Nepal

5. The socio demographic factors such as unmarried civil status $(\mathrm{OR}=3.3)$, unemployment $(\mathrm{OR}=3.4)$, living in rural area $(\mathrm{OR}=4)$ and nuclear family setup $(\mathrm{OR}=6)$ were significant risk factors.

6. Many risk factors were related to the DOTS.

\section{Acknowledgement:}

The authors acknowledge to the Director and Staff of NTP Nepal \& Mr. Sanjeeb Jha, Statistician, STAC for data entry and analysis.

\section{RE COMMENDATION:}

1. Analysis of risk factors for MDR-TB are useful for improving programme performance and should be undertaken in other member states also in the SAARC region where prevalence of MDR-TB is high.

2. Further development of MDR-TB should be prevented by sensitizing private practitioners, community members and specialists on issues related to development of drug resistance. This study results can be used as a tool for this.

3. A National HIV prevalence survey among MDR-TB patients should be carried out every two years not only in Nepal but also in other SAARC Countries.

4. Travel cost more than 50 NPR per day and distance to DOTS centre more than $5 \mathrm{KM}$ were significant risk factors for MDR-TB. Accessibility of services should be improved especially in rural areas where the patients have to travel long distance to avail the services. Currently MDR-TB patients are getting some allowance in Nepal to attend the clinic. If possible, in addition, this allowance should also be extended to poor drug sensitive TB patients to enhance treatment adherence and better patient's compliance.

5. DOT for both drug sensitive tuberculosis and drug resistance tuberculosis should be strictly adhered to.

6. Strengthening of DOTS programme to overcome the identified risk factors can reduce the MDR-TB burden in Nepal.

\section{REFERENCE:}

1. Anderson RM. The pandemic of antibiotic resistance. Nature Med 1999;5:147-149

2. WHO Report 2014, GLOBAL TUBERCULOSIS CONTROL World Health Organization Geeneva,2014

3. Leweanga SK, Lemeshow S. Sample size determination in health studies. A practical
Manual.World Health Organization. 1991:10

4. Frederick $A D$ et al $A n$ assessment of factors contributing to treatment and knowledge of TB transmission among patients on TB treatment - BMC public health 2004; 4:68

5. Ahmed A.M et al Risk factors for MDR-TB among patients with Pulmonary TB ; a case control study in Karachi, Pakistan; Book of abstract 22 ${ }^{\text {nd }}$ IUATLD Eastern Regional Conference-2003

6. Pablo E, Campos $P$ et al. MDR-TB in HIV infected person- Peru 2003. Emerging Infectious Disease

7. Casal $\mathrm{M}$, Vaquero $\mathrm{H}$ et al A case control study for Multidrug- Resistant TB: Risk factors in four European Countries. Microbial Drug Resistance, 2005 11(1); 62-67 International Journal of Tubercle and Lung Disease 7 (9)861-872.

8. Anti TB drug resistance in the world. Report prevalence and trends. The WHO/IUATLD. Global project on anti TB drug resistance Surveillance. WHO/CDS/TB/2000.278, Genewa

9. Dosso $M$ et al. Primary resistance to anti TB drugs. A national survey conducted in Cote d'Ivoire in 1995-1996. International Journal of Tubercle and Lung disease 1998:3:805-809.

10. Bercion $\mathrm{R}$ et al. Initial resistance to anti TB drugs in Yaounde, Cameroon in 1995. International Journal of Tubercle and Lung disease 1997;1:110-114

11. Wilkinson $D$ et al, Resistance to Anti TB drugs in rural South Africa; rates, patterns, risk and transmission dynamics. Tropical Medicine Hygine, 1996: 90:692-695.

12. Guidelines for the programmatic management of drug- resistant tuberculosis. 2006, World Health Organization pp -27,

13. WHO Stop TB Partnership, The global plan to stop TB.WHO/CDS/STB/2001.16.Geneva, Switzerland; WHO, 2002.

14. Boyte S.J.O., J.P.Watson,J.J Power.Factors affecting patients compliance with anti TB chemotherapy using the DOTS. International Journal of Tubecle and Lung Disease, 6(4), 307-312.

15. R.Corcoran. Compliance with chemotherapy for TB. Irish Medical Journal 1986; 79; 87-90.

16. Espinal M.A, S.J.Kim, P.G.Suarez P.G. et al. Standard short course chemotherapy for drug resistant TB. JAMA, 2000, 283:2537-2542.

17. Annual report-2013 National TB Programme, Nepal 